\title{
Prevalence and associated factors of bed bug infestations (Cimex lectularius) in lubaga division, Kampala capital city, Uganda
}

\author{
George W Senabulya, John B Alege, Christine Atuhairwe and Ivan M Taremwa* \\ Clarke International University, Uganda
}

\begin{abstract}
Background: There has been an increasing public health concern as a result of bed bug infestation, with devastating effects on health and quality of life in Uganda. This study provided the first community-based report on the situation of bed bugs in Lubaga division, Kampala Capital City, Uganda.

Methods: This was a descriptive cross-sectional study design, in which data was collected using questionnaire, key informant interview guide and a data abstraction tools.

Results: Out of the 356 respondents interviewed, 249(69.9\%) had bed bugs in their homes. The study further revealed a significant statistical relationship between the variables of gender, sex, level of education, employment status. The health systems factors that include availability of professional personnel to control bed bugs, use of effective and recommended chemicals, availability of funds, and resistance of bed bugs to insecticides were all found to have an influence on the risk of bed bugs.
\end{abstract}

Conclusion: The study has established the need to strengthen vector control programs in a city suburb.

\section{Background}

Bed bugs (Cimex lectularius) are blood-feeding insects that have plagued humans for thousands of years [1]. They have been a household pest issue for more than 3,300 years, dating back to ancient Egypt. During the latter half of the 20th century, this bloodfeeding species was almost extinct in many economically developed countries due to the widespread use of synthetic pesticides such as Dichlorodiphenyltrichloroethane (DDT) [2]. In recent years, however, there was a surge of reports of bed bug infestations among the developed countries [2-4]. Bed bugs belong to the Cimicidae family that feed exclusively on the blood of mammals, in particular human beings, or birds [2,5] and this affects the quality of life and is a mechanism of disease transmission and are common public health pests in many parts of Uganda.

Despite efforts to eliminate bed bugs by use of common pesticides and heat, there has been increasing public health problem as a result of bed bug increased infestation in Uganda. Infestation with Cimex lectularius is linked to a risk of transmitting Trypanosoma cruzi, the etiologic agent of Chagas disease [6]. With increased resistance to common pesticides such as chlorfenapyr, permethrin, and pyrethroids $[7,8]$ it has become a critical challenge. Bed bug infestations can have adverse effects on health and quality of life as victims have been reported to suffer from loss of sleep, psychological distress, as well as allergic reactions [9]. Vigorous scratching and concomitant erosions predispose the skin to secondary bacterial infection, while chronic blood loss and iron-deficiency anemia have also been reported in people who have been continuously exposed to severe bed bug infestations. Bed bug infestations have been reported in places such as homesteads, schools, institutions, hotels, public transport, refugee camps and other places in Uganda. There is limited epidemiological data on bed bugs in Uganda. We report on the prevalence and risk factors for bed bug infestations in Lubaga division, Kampala capital city, Uganda.

\section{Materials and methods}

\section{Design}

This was a descriptive cross-sectional study design involving purely quantitative method. Data were collected in the following part of Kampala; Busega, Kasubi, Kawaala, Kizito Block Najja II, Kosovo (Bukooza), Lungujja-Kintunzi, Mutundwe, Wabiyinja, Najjanankumbi, Namirembe Bakuli, Namungoona, Nankulabye, Nateete, Ndeeba and Wankulukuku.

\section{Data collection and management}

Data collection tools that were used included a questionnaire, key informant interview guide and a data abstraction tool for the quantitative component of the study.

\section{Data tools}

These included semi-structured researcher administered questionnaires. Respondents were asked questions in languages they understood properly.

*Correspondence to: Ivan Mugisha Taremwa, Clarke International University, P.O Box 7782, Kampala, Uganda, Tel: +256774346368; Email: imugisha@ymail.com

Key words: associated factors, bedbug (cimex lectularius), infestation, vector control

Received: March 29, 2019; Accepted: April 10, 2019; Published: April 18, 2019 


\section{Ethical consideration}

Ethical approval was obtained from Clarke International University (Formerly, International Health Sciences University). In addition, permission was sought from Kampala Capital City Authority (KCCA), Ministry of Health (MOH), Local Councils (I, II and III). At an individual level, written informed consent was obtained from each participant.

\section{Results}

\section{Analysis of individual factors}

Thirty-one participants (8.7\%) were aged $15-20$ years, $82(23.0 \%)$ $21-25$, more than a quarter $96(27.0 \%)$ were aged $26-30$ years. Also, $251(70.5 \%)$ of the participant were female, $76(21.3 \%)$ had attained primary education, and a half $183(51.4 \%)$ attained secondary level of education. $206(57.9 \%)$ of the respondents were employed while 150(42.1\%) were unemployed, details are given in table 1 .

\section{Social factors influencing bedbug infestation}

Three hundred and forty $(\mathrm{N}=340,95.5 \%)$ of the participant had knowledge about bed bugs and had varied skills to identify them. Only 43 (12.1\%) used reddish brown spots on the mattresses and furniture to identify presence of bed bugs, $43(12.1 \%)$ used presence of eggs in fabric seams, $33(9.3 \%)$ of them were identified using a foul odor from oily secretions. 35 (9.8\%) of the participants identified presence of bed bugs using fecal spots left around points of entry and exit to their hiding places, 84 (23.6\%) used bite symptoms to identify presence of bed bugs, $49(13.8 \%)$ used blood smears on sheet and clothes while $37(10.4 \%)$ used moults and $72(20.2 \%)$ identified presence of bed bugs using

Table 1. Bivariate analysis of the individual attributes on bedbug infestation

\begin{tabular}{|c|c|c|c|c|c|}
\hline \multirow{2}{*}{ Variable } & \multicolumn{3}{|c|}{ Infested with bedbugs } & \multicolumn{2}{|c|}{ Statistical test } \\
\hline & Yes & No & Total & $\mathbf{X}^{2}$ & $p$-value \\
\hline \multicolumn{6}{|l|}{ Age category } \\
\hline $15-20$ & $16(6.4)$ & $15(14.0)$ & 31 & $12.566^{\mathrm{a}}$ & .028 \\
\hline $21-25$ & $52(20.9)$ & $30(28.0)$ & 82 & & \\
\hline $26-30$ & $65(26.1)$ & $31(29.0)$ & 96 & & \\
\hline $31-35$ & $64(25.7)$ & $17(15.9)$ & 81 & & \\
\hline $36-40$ & $25(10.0)$ & $6(5.6)$ & 31 & & \\
\hline$<40$ & $27(10.8)$ & $8(7.5)$ & 35 & & \\
\hline Total & 249 & 107 & 356 & & \\
\hline \multicolumn{6}{|l|}{ Sex } \\
\hline Female & $182(73.1)$ & $69(64.5)$ & 251 & $2.666^{\mathrm{a}}$ & .103 \\
\hline Male & $67(26.9)$ & $38(35.5)$ & 105 & & \\
\hline Total & 249 & 107 & 356 & & \\
\hline \multicolumn{6}{|l|}{ Level of education } \\
\hline Primary & $52(20.9)$ & $24(22.4)$ & 76 & $7.914^{\mathrm{a}}$ & .095 \\
\hline Secondary & $124(49.8)$ & $59(55.1)$ & 183 & & \\
\hline High school (HSC) & $22(8.8)$ & $8(7.5)$ & 30 & & \\
\hline Tertiary & 19(7.6) & $12(11.2)$ & 31 & & \\
\hline No education & $32(12.9)$ & $4(3.7)$ & 36 & & \\
\hline Total & 249 & 107 & 356 & & \\
\hline \multicolumn{6}{|l|}{ Employment status } \\
\hline Employed & $136(54.6)$ & $70(65.4)$ & 206 & $3.582^{\mathrm{a}}$ & .058 \\
\hline Unemployed & $113(45.4)$ & $37(34.6)$ & 150 & & \\
\hline Total & 249 & 107 & 356 & & \\
\hline \multicolumn{6}{|l|}{ Type of employment } \\
\hline Civil servant & $39(15.7)$ & $35(32.7)$ & 74 & $17.528^{\mathrm{a}}$ & $.000^{* *}$ \\
\hline Business person & $97(39.0)$ & $44(41.1)$ & 141 & & \\
\hline Peasant & $113(45.4)$ & $28(26.2)$ & 141 & & \\
\hline Total & 249 & 107 & 356 & & \\
\hline
\end{tabular}

*Statistically significant $p<0.05$ physical presence. The study finding also indicated that 154 (43.3\%) of the participant agreed that visitors led in to bed bugs infestation in their homes, 68 (19.1\%) revealed that it is transferred from school by children in to their homes, $75(21.1 \%)$ agreed that buying second hand clothes leads in to manifestation of bed bugs in their homes. In addition to that, $43(12.1 \%)$ of the respondents agreed that they carry bed bugs from taxis to their home while $115(32.3 \%)$ revealed that it moves from their neighbors and 32 (9.0\%) got them from hotels/guest houses. In regard to method used to control bed bugs, $144(40.4 \%)$ of the respondent used application of chemicals, 76 (21.3\%) used hot water to burn them, while $59(16.6 \%)$ of the participant washed their clothes and bedding to control bed bug infestation in their homes. Out of 356 participants, almost a half 175 (49.2\%) of them agreed that they used insecticides to control bed bugs while 181 (50.8\%) did not use insecticides. The social characteristics were analyzed to determine their significant association with bed bugs infestation. The study established that bed bug infestation was significantly influenced by: having knowledge about bed bugs ( $\mathrm{X}^{2} 8.388$, p-value 0.004), identification with reddish brown spots $\left(\mathrm{X}^{2} 3.997\right.$, $p$-value 0.046$)$, Bite symptoms $\left(\mathrm{X}^{2} 4.017\right.$, p-value 0.045), physical presence of bed bugs ( $\mathrm{X}^{2} 10.828$, p-value 0.001$)$, visitors ( $\mathrm{X}^{2} 8.218$, p-value 0.004), neighbors ( $\mathrm{X}^{2} 9.646$, $\mathrm{p}$-value 0.002$)$, burning with hot water $\left(\mathrm{X}^{2} 4.121, p\right.$-value 0.042$)$ and employment of qualified personnel $\left(\mathrm{X}^{2} 6.159\right.$, $p$-value 0.013$)$, these factors are presented in table 2.

\section{Results of multivariate logistic regression analysis}

Using logistic regression analysis, age category of 15-20years $(\mathrm{OR}=3.133,95 \%$ CI 1.011-9.703, $\mathrm{p}=.048)$, primary education level (OR 3.863, 95\% CI 1.132-13.183, $p=.031$ ), secondary level of education (OR 3.605, 95\% CI 1.119-11.610, $p=.032$ ), being employed (OR 2.4.093, 95\% CI .759-22.078), being a civil servant (OR 4.292, 95\% CI $2.204-$ $8.384, p=.000$ ), presence of bed bug eggs in fabric seams (OR 3.593, $95 \%$ CI 1.859-6.944, $p=.000$ ), bite symptoms (OR 2.251, 95\% CI 1.172$4.322, p=.015)$, visitors as a source of bed bugs $(\mathrm{OR}=2.017,95 \% \mathrm{CI}$ 1.222-3.329, $p=.006$ ), schools (OR 1.952, 95\% CI .984-3.874, $p=.056$ ), neighbors and friends complaining about bed bugs (OR 7.549, 95\% CI 4.086-13.945), lack of effective chemicals for bed bugs (OR 2.067, 95\% CI 1.065-4.012, $p=.032$ ) and no proper skilled person to spray the bed bugs (OR 2.035, 95\% CI 1.197-3.461, $p=.009$ ) were factors that predicted bed bug infestation in Lubaga division. This means that among those aged 15-20 years were 3.1 times more likely to be infested with bed bugs, as shown in table 3 .

\section{Discussion}

This study has found an overwhelming $70 \%$ prevalence of bed bugs in Lubaga division. Also, 249 (69.9\%) had bed bugs in their homes. This is in agreement with a door to door study in a residential census tract of Philadelphia USA by Yage et al. [10]. According to that report, among the 596 respondents, $66(11.1 \%)$ reported having bed bugs in their residence and were classified as reported positive. This also correlates with a study by Eliningaya et al. [11] which indicated that $1370(51.3 \%)$ bed bugs were collected from houses with no bed nets and 980 (36.8\%) bed bugs were collected from houses with torn bed nets, since this could be an indicator of the populations' financial capacity to buy and utilize intact bed nets. The high prevalence was attributed to both the individual and health systems factor because there was positive correlation between these factors and bed bug infestation. During the analysis, it was found that the very poor respondents and the economically-disadvantaged individuals had significant increased chances of being infected with bed bugs. 
Table 2. Influence of social factors on bed bug infestation

\begin{tabular}{|c|c|c|c|c|c|}
\hline \multirow{2}{*}{ Variables } & \multicolumn{2}{|c|}{ Home infested with bed bugs } & \multirow{2}{*}{$\begin{array}{l}\text { Total } \\
\text { Total }\end{array}$} & \multicolumn{2}{|c|}{ Statistical test } \\
\hline & Yes & No & & $\mathbf{X}^{2}$ & $p$-value \\
\hline \multicolumn{6}{|l|}{ Do you know bed bug } \\
\hline Yes & 243(97.6) & $97(90.7)$ & 340 & $8.388^{\mathrm{a}}$ & $.004 * *$ \\
\hline No & $6(2.4)$ & $10(9.3)$ & 16 & & \\
\hline Total & 249 & 107 & 356 & & \\
\hline \multicolumn{6}{|l|}{ Signs used to identify bed bugs } \\
\hline Reddish brown spots on mattress/furniture & $62(25.5)$ & $15(15.5)$ & 77 & 3.997 & $.046^{* *}$ \\
\hline Presence of eggs & $107(44.0)$ & $16(16.5)$ & 123 & 22.770 & .000 \\
\hline Foul odor & $18(7.4)$ & $8(8.2)$ & 26 & .069 & .792 \\
\hline Excrement (fecal spots) & 21(8.6) & $7(7.2)$ & 28 & .186 & .666 \\
\hline Bite symptoms & $65(26.7)$ & $16(16.5)$ & 81 & 4.017 & $.045^{*}$ \\
\hline Blood smear & $52(21.4)$ & $21(21.6)$ & 73 & .003 & .960 \\
\hline Moults (shed skins) & $31(12.8)$ & $17(17.5)$ & 48 & 1.300 & .254 \\
\hline Physical presence & $128(52.7)$ & $70(72.2)$ & 198 & 10.828 & $.001 *$ \\
\hline \multicolumn{6}{|l|}{ What leads to bed bugs infestation } \\
\hline Visitors & $120(48.2)$ & $34(31.8)$ & 154 & $8.218^{\mathrm{a}}$ & $.004 *$ \\
\hline School transfer & $54(21.7)$ & $14(13.1)$ & 68 & $3.584^{\mathrm{a}}$ & .058 \\
\hline Buying second hand & $53(21.3)$ & $22(20.6)$ & 75 & $.024^{\mathrm{a}}$ & .878 \\
\hline Taxi & $28(11.2)$ & $15(14.0)$ & 43 & .542 & .462 \\
\hline Neighbors & $93(37.3)$ & $22(20.6)$ & 115 & $9.646^{\mathrm{a}}$ & $.002 *$ \\
\hline Hotels & $20(8.0)$ & $12(11.2)$ & 32 & $.927^{\mathrm{a}}$ & .336 \\
\hline \multicolumn{6}{|l|}{ Methods used to control bed bugs } \\
\hline Chemicals & $129(55.4)$ & $43(87.8)$ & 172 & 17.853 & .000 \\
\hline Burning with hot water & $93(39.9)$ & $12(24.5)$ & 105 & 4.121 & $.042 * *$ \\
\hline Washing with hot water & $59(25.3)$ & $8(16.3)$ & 67 & 1.809 & .179 \\
\hline \multicolumn{6}{|l|}{ Use insecticides } \\
\hline Yes & $129(51.8)$ & $46(43.0)$ & 175 & $2.328^{\mathrm{a}}$ & .127 \\
\hline No & $120(48.2)$ & $61(57.0)$ & 181 & & \\
\hline Total & 249 & 107 & 356 & & \\
\hline \multicolumn{6}{|l|}{ Type of insecticide } \\
\hline Don't know & $220(88.4)$ & $93(86.9)$ & 313 & $4.014^{\mathrm{a}}$ & .547 \\
\hline Aerosols & $8(3.2)$ & $6(5.6)$ & 14 & & \\
\hline Organophosphates & $3(1.2)$ & $2(1.9)$ & 5 & & \\
\hline Pyrethroids & $12(4.8)$ & $4(3.7)$ & 16 & & \\
\hline Carbamates & $4(1.6)$ & $0(0.0)$ & 4 & & \\
\hline Organochlorides & $2(.8)$ & $2(1.9)$ & 4 & & \\
\hline Total & 249 & 107 & 356 & & \\
\hline \multicolumn{6}{|l|}{ Employ qualified person } \\
\hline Yes & $12(4.8)$ & $13(12.1)$ & 25 & $6.159^{\mathrm{a}}$ & .013 \\
\hline No & $237(95.2)$ & $94(87.9)$ & 331 & & \\
\hline Total & 249 & 107 & 356 & & \\
\hline \multicolumn{6}{|l|}{ Challenges do you find in control } \\
\hline Don't die & $94(37.8)$ & $81(75.7)$ & 175 & $46.416^{\mathrm{a}}$ & .000 \\
\hline Return very fast & $146(58.6)$ & 21(19.6) & 167 & & \\
\hline No enough money & $9(3.6)$ & $5(4.7)$ & 14 & & \\
\hline Total & 249 & 107 & 356 & & \\
\hline
\end{tabular}

*Statistically significant $p<.05$

There was a significant relationship found between the gender of the respondent $\left(\mathrm{X}^{2} 12.566 \mathrm{p}\right.$-values .028) and bedbug infestation. This could be attributed to the different lifestyles. The females tend to have congested rooms due to an increased number of clothes which agrees with a publication by Pest management Consultancy in United Kingdom, (2008). This study reported that congested domestic premises make bed bug control difficult while the males could be attributed to the question of personal hygiene. The results indicated age categories of 26-35 participated more in the study, 96 (27.0\%) were aged 26-30 years, $81(22.8 \%)$ were between $31-35$ years. These were all household heads or guardians with responsibility of the home. With the high prevalence of bed bugs in their homes, it implies that this age group is most at risk. This was confirmed by a significant causal relationship between age category $15-20$ years $(\mathrm{OR}=3.133,95 \%$ CI 1.011-9.703, $p=.048)$ and bedbug infestation. The age group is believed to be that of a lower income status which proves the argument that bed bugs affect more of the poor people in communities. There was a correlation between level of education and bed bug infestation. The majority of participants had primary level of education which further indicated a causal relationship (OR 3.863, 95\% CI 1.132-13.183, $p=.031$ ), and secondary level of education (OR 3.605, 95\% CI 1.119-11.610, $p=.032$ ). Generally, there is an association of bed bug infestation with both low income levels and the education status. The confirmation that the low-income communities experienced high bed bug infestation trajectory agrees 
Table 3. Results of multivariate analysis

\begin{tabular}{|l|l|l|l|l|}
\hline Variable & Sig & OR & Lower & Upper \\
\hline Age group (15-20 years) & .048 & 3.133 & 1.011 & 9.703 \\
\hline Age group (21-25 years) & .258 & 1.764 & .660 & 4.718 \\
\hline Education level (Primary) & .031 & 3.863 & 1.132 & 13.183 \\
\hline Education level (Secondary) & .032 & 3.605 & 1.119 & 11.610 \\
\hline Education level (High school certificate) & .297 & 2.157 & .509 & 9.133 \\
\hline Education level (Tertiary) & .058 & 3.879 & .958 & 15.712 \\
\hline Employment status (Employed) & .007 & 2.292 & 1.259 & 4.173 \\
\hline Type of employment (Civil servant) & .000 & 4.299 & 2.204 & 8.384 \\
\hline Sign of bed bugs (eggs in fabric seams) & .000 & 3.593 & 1.859 & 6.944 \\
\hline Sign of bed bugs (Bite symptoms) & .015 & 2.251 & 1.172 & 4.322 \\
\hline Source of bed bugs (visitors) & .006 & 2.017 & 1.222 & 3.329 \\
\hline Source of bed bugs (school) & .056 & 1.952 & .984 & 3.874 \\
\hline Challenges in controlling bed bugs(they don't die easily) & .216 & 3.164 & .511 & 19.582 \\
\hline Neighbors complaining about bed bugs & .000 & 7.549 & 4.086 & 13.945 \\
\hline Use of Chemical to control bed bugs & .240 & 1.969 & .636 & 6.089 \\
\hline Department (Lubaga health office) & .292 & 1.808 & .601 & 5.445 \\
\hline Department (village health teams) & .213 & 3.414 & .494 & 23.596 \\
\hline Department (NGOs) & .193 & 2.014 & .701 & 5.787 \\
\hline Why bed bugs persist (lack of effective chemicals) & .032 & 2.067 & 1.065 & 4.012 \\
\hline Why bed bugs persist (no proper skilled people) & .009 & 2.035 & 1.197 & 3.461 \\
\hline Why bed bugs persist (resistance of bed bug) & .086 & 1.817 & .918 & 3.596 \\
\hline
\end{tabular}

*Statistically significant $p<.05$

with earlier literature [12]. With low income levels, people cannot afford to employ professional personnel to help in controlling bed bugs from their homes; neither can they afford to buy the recommended insecticides to spray. The employment status ( $\mathrm{X}^{2} 3.582$ p-value .058) was also found to have a significant correlation. This could be attributed to the fact that both the employed and the unemployed are involved in the transmission of the bed bugs. The employed could acquire them from different work places while the unemployed could acquire them from home visitations. Therefore, this leaves both at a significant risk of being infested with bed bugs. The study confirmed that being employed (OR 2.4.093, 95\% CI .759-22.078), was associated with bed bug infestation. The type of employment showed a positive correlation $\left(\mathrm{X}^{2} 17.528\right.$, p-value .000$)$ with bedbug infestation. For example, being a civil servant (OR 4.292, 95\% CI 2.204-8.384, $p=.000$ ) was associated with bedbug infestation. This is probably attributed to the large numbers of people they directly come into contact with and the unmatched low level of hygiene.

There was a positive correlation between bedbug infestation and knowledge (identification with reddish brown spots $\left(\mathrm{X}^{2} 3.997, p\right.$-value 0.046), bite symptoms $\left(\mathrm{X}^{2} 4.017, p\right.$-value 0.045$)$, physical presence of bed bugs $\left(\mathrm{X}^{2} 10.828\right.$, $p$-value 0.001$)$. This could be related to the multiple exposures of the communities, and thus have full recognition. This agrees with Goddard and deShazo [13], who indicated that bed bugs plague humans and Bonnefory et al. [2] who described the common bed bugs as having a light cream appearance, but progressively becoming reddish-brown in color. This proves that bed bugs are a serious problem in Lubaga division and many of them never hesitated to admit into their houses research assistants to see how badly off they are with hope that one day, they will be saved from this nuisance biter. Majority of respondents used bite symptoms to identify presence of bed bugs in their homes followed by the physical presence of bed bugs and blood smears on bed sheets (OR 3.593, 95\% CI 1.859-6.944, $p=.000$ ). Bed bugs have very painful bites as indicated by a significant number of respondents who indicated that the biting symptoms (OR $2.251,95 \%$ CI $1.172-4.322, p=.015$ ) were used to identify these bed bugs. Sometimes one can develop red spots at the bite site due to body reactions. Bed bugs are shy to light and sound vibrations. It is therefore not very easy to observe physical presence of bed bugs unless when the infestation is considerably high. According to the study findings, majority of participants agreed that visitors to their homes $(\mathrm{OR}=2.017$, $95 \%$ CI 1.222-3.329, $p=.006$ ), were the leading source of bed bugs into their homes followed by the close neighborhoods, second hand clothes and schools where children. This is in line with findings from a report by the Pest management Consultancy in United Kingdom, (2008). This was also confirmed by respondents who indicated that the neighbors and friends were complaining about bed bugs (OR 7.549, 95\% CI 4.086-13.945). In regard to methods used to control bed bugs, most respondents $144(40.4 \%)$ used application of chemical to control them, while $76(21.3 \%)$ used hot water for burning them. The use of hot water is probably due to lack of enough knowledge in bed bug control because eggs of the species Cimex lectularius are quite resistant to hot temperatures. In view of the above, out of 356 study participants, almost a half $175(49.2 \%)$ of them agreed that they used insecticides to control bed bugs while 181(50.8\%) did not use insecticides. This implies that residents of Lubaga division believe that with effective chemicals, bed bugs can be eliminated. Nevertheless, majority of them did not use these insecticides probably because they are not available, affordable or accessible. With reference to type of insecticides used to control bed bugs, majority ( $\mathrm{N}=313,87.9 \%)$ did not know the type of the insecticides they could use to control bed bugs. This confirms a knowledge gap about the various insecticides in control of bed bugs. This calls for the relevant authorities to sensitize the community about the dangers of insecticides and the safest ways to administer pesticides. Most participants $(\mathrm{N}=331,93.0 \%)$ disagreed that they had qualified people to help in control of bed bugs. This concurs with previous research [10], who maintained that inadequate training of pest control technicians contributes greatly to the resurgence and spread of bed bugs. The challenges faced in control of bed bugs according to the study indicated that $175(49.2 \%)$ of the respondents agreed that the bed bugs don't die, $167(46.9 \%)$ revealed that it comes back very fast and 14(3.9\%) agreed that they don't have money to control them. This is probably because of the lack of knowledge in bed bug prevention and control and the ineffective chemicals. Further, poor techniques of chemical application and the equipment used was found wanting. Many respondents revealed that they could buy any unknown chemicals from street vendors and use bottles with punctures to apply the chemical to kill the bed bugs. One of the respondents said that "Bwetufuuyila nga tukozesa obukebe buno, ebiku tebifa. Ate abayitamu nga bafuuyila oyinza okulowooza nti babyoogedde bwongezi busuungu kutuluma. Bafuuyila mazzi meerere". Literally meaning that, "when we spray using the punctured bottles, bed bugs don't die. And it's as if the people who pass through our villages spraying only excite them to bite us the more. It seems they use water to spray bed bugs". There is a correlation between bed bug infestation and visitors ( $\mathrm{X}^{2} 8.218, p$-value 0.004$)$ and neighbors $\left(\mathrm{X}^{2} 9.646\right.$, p-value 0.002 ) as they are carried by humans in seams of clothes. This agrees with the fact that bed bugs can rapidly spread to neighboring units and cause high infestation rates in multiunit dwellings [4,7]. These studies also asserted that in most cases, bed bugs are transported from infested areas to non-infested areas when they cling onto someone's clothing, or crawl into luggage, furniture or bedding that is then brought into homes. This justifies the relationship between the visitors, neighbors and bedbug infestation. The study found that the methods of bedbug control among the community was lacking. This was for example justified by the strong relationship between infestation of bedbug and use of burning with hot water $\left(\mathrm{X}^{2} 4.121\right.$, p-value 0.042$)$ as a method of controlling bed bugs. This is attributed to the limited knowledge 
considering the fact that they were employing unqualified personnel $\left(\mathrm{X}^{2} 6.159, p\right.$-value 0.013$)$ to control the bed bugs.

\section{Conclusion}

Based on these, bed bugs represent a very big challenge to public health in Lubaga division and Uganda at large as evidenced by the high prevalence $(70 \%)$. The study has further established the need to strengthen vector control programs in a city suburb.

\section{Acknowledgement}

The authors would like to thank the residents of Lubaga division who participated in the study.

\section{Funding}

We did not receive funding for this study.

\section{Availability of data and materials}

We have not obtained permission to share data obtained from the Lubaga division. However, the data set can be availed on request from the corresponding author.

\section{Ethics approval and consent to participate}

We received ethical approval from International Health Sciences University Research Ethics Committee (REC). All respondents provided written informed consent after receiving detailed description of the study. Eligible participants were consented in privacy and no incentives were given. Anonymity of the respondents was ensured at all stages of data analysis.

\section{Competing interests}

The authors declare no conflict of interest in this work.

\section{References}

1. Goddard J, deShazo R (2009) Bed bugs (Cimex lectularius) and clinical consequences of their bites. JAMA 301: 1358-1366. [Crossref]

2. Bonnefory X, Kampen H, Sweeney K (2008) Public Health Significance of Urban Pests. Copenhagen, Denmark: World Health Organization.

3. Bauer-Dubau K (2004) Invasion in deutschen Betten: Bettwanzen. Arzte Zeitung 176179

4. Doggett SL, Orton CJ, Lilly DG, Russell RC (2011) Bed Bugs: The Australian Response. Insects 2: 96-111. [Crossref]

5. Heukelbach J, Hengge UR (2009) Bed bugs, leeches and hookworm larvae in the skin. Clin Dermatol 27: 285-290. [Crossref]

6. Salazar R, Castillo-Neyra R, Tustin AW, Borrini-Mayorí, K, Náquira C, et al. (2015) Bed bugs (Cimex lectularius) as vectors of Trypanosoma cruzi. Am J Trop Med Hyg 92: 331-335. [Crossref]

7. Doggett S (2009) The resurgence of bed bugs. In: (Doggett S, ed). Sydney: The Department of Medical Entomology, Westmead Hospital. Environmental Health 30-38.

8. Boase CJ (2007) Bed bugs - research and resurgence. In: Takken W and Knols, BJ, eds Emerging pests and vector borne diseases in Europe. Ecology and control of Vector borne disease.

9. Hwang SW, Svoboda TJ, De Jong IJ, Kabasele KJ, Gogosis E (2005) Bed bug infestations in an urban environment. Emerg Infect Dis 11: 533-538. [Crossref]

10. Wu Y, Tracy DM, Barbarin AM, Barbu CM, Levy MZ (2014) A Door-to-Door Survey of Bed Bug (Cimex lectularius) Infestations in Row Homes in Philadelphia, Pennsylvania Am J Trop Med Hyg 9; 206-210. [Crossref]

11. Eliningaya J Kweka, Beda J Mwang'onde, Epiphania E Kimaro, Shandala Msangi, Filemoni Tenu, et al. (2009) Insecticides Susceptibility Status of the Bedbugs (Cimex lectularius) in a Rural Area of Magugu, Northern Tanzania. J Glob Infect Dis 1:102106. [Crossref]

12. The Pest Management Consultancy UK (2008) Bed bugs (hemiptera: cimicidae): An evidence-based analysis of the current situation. Sixth International Conference on Urban Pests.

13. Romero A, Potter MF, Potter DA, Haynes KF (2007) Insecticide resistance in the bed bug: a factor in the pest's sudden resurgence? J Med Entomol 44: 175-178. [Crossref]

Copyright: (2019 Senabulya GW. This is an open-access article distributed under the terms of the Creative Commons Attribution License, which permits unrestricted use, distribution, and reproduction in any medium, provided the original author and source are credited. 